\title{
PELATIHAN PEMBUATAN GAME MENGGUNAKAN GDEVELOP UNTUK SISWA/I SMA NEGERI 6 PALEMBANG
}

\author{
Yohannes'), Siska Devella'), Meiriyama²) \\ 1)Informatika, Fakultas IImu Komputer dan Rekayasa, Universitas Multi Data Palembang, Palembang, \\ Sumatera Selatan, Indonesia \\ ${ }^{2}$ Manajemen Informatika, Fakultas IImu Komputer dan Rekayasa, Universitas Multi Data Palembang, Palembang, \\ Sumatera Selatan, Indonesia \\ Corresponding author : Siska Devella \\ E-mail : siskadevella@mdp.ac.id
}

Diterima 30 November 2021, Direvisi 09 Desember 2021, 09 Desember 2021

\begin{abstract}
ABSTRAK
Kegiatan pengabdian kepada masyarakat dalam bentuk pelatihan pembuatan game dengan menggunakan GDevelop memiliki tujuan yaitu untuk memberikan wawasan kepada siswa dan siswi SMA Negeri 6 Palembang dalam menggunakan aplikasi GDevelop yang dapat digunakan untuk membuat game sehingga dapat menambah keterampilan dan wawasan. Terdapat tiga tahapan utama yang dilakukan dalam pengabdian ini antara lain perencanaan, implementasi dan terakhir adalah evaluasi dengan memberikan tautan kuesioner berupa google form. Hasil kuesioner menunjukkan bahwa didapatkan rata-rata $96,8 \%$ peserta merasakan manfaat dan sangat setuju dengan pelatihan yang telah dilakukan.
\end{abstract}

Kata kunci: game; gdevelop; pelatihan; pengabdian kepada masyarakat.

\begin{abstract}
Community service activities in the form of training in making games using GDevelope aim to provide insight to students of SMA Negeri 6 Palembang in using the GDevelop application for making of the video games, so the students can add skills and insights. There are three main stages carried out in this service, including planning, implementation and finally evaluation by providing a questionnaire link in the form of a google form. The results of the questionnaire showed that an average of $96.8 \%$ of participants feel the benefits and strongly agreed with the training that had been carried out.
\end{abstract}

Keywords: community service activities; game; gdevelop training.

\section{PENDAHULUAN}

Beberapa tahun terakhir ini, penggunaan game sebagai konsep untuk tujuan pendidikan semakin populer dan banyak digunakan baik untuk Sekolah dasar maupun tingkat lebih lanjut. Game dapat digunakan untuk memotivasi pengguna dalam mendukung pembelajaran sehingga dapat mencapai hasil belajar yang lebih baik (Noemí \& Máximo,2014). Game merupakan jenis permainan dimana pemain mengikuti aturan-aturan yang telah ditentukan (Samuel Zirawaga \& Idowu Olusanya Tinovimbanashe Maduku,2017), (Aula et al.,2020). Kebanyakan game menuntut pemain untuk berpikir cepat. Selain itu, pemain juga harus menggunakan logika mereka untuk berpikir tiga langkah ke depan dalam menyelesaikan masalah dan menyelesaikan level permainan. Hal ini akan sangat bermanfaat di kemudian hari karena dapat mengembangkan logika, akurasi, dan kemampuan untuk berpikir secara mandiri dan di luar kebiasaan. Banyak game yang mengandung aspek-aspek logika sehingga dapat membantu pemain dengan keterampilan tertentu. Sebagai contoh, game misteri dan petualangan yang berisikan peta yang harus dibaca dan diselesaikan oleh pemain. Ini jelas membantu keterampilan membaca peta dan pemikiran praktis mereka.

Menurut data asosiasi IP Development, Cipta Kreasi (CAKRA) pada tahun 2018, pasar game di Indonesia mencapai angka US\$ 1.13 miliar, akan tetapi game lokal buatan Indonesia hanya menguasai sekitar $0.2 \%$ saja (Qomariah et al.,2020). Oleh karena itu, pentingnya dalam menumbuhkan dan menciptakan developerdeveloper game agar dapat bersaing di pangsa Indonesia.

Perancangan game adalah konteks yang berguna untuk mengembangkan pemikiran komputasi dan kreativitas digital. Ketika peserta didik diperkenalkan dengan pengembangan perangkat lunak, maka peserta didik membutuhkan konteks yang mudah untuk dipahami. Game menghadirkan dunia dengan 
tujuan yang jelas, aturan-aturan yang ditentukan, dan memungkinkan untuk mempunyai lebih dari satu solusi untuk suatu masalah. Untuk menjadi pengembang game pemula, GDevelop adalah solusi yang baik dan sempurna karena memiliki beberapa keunggulan diantaranya yaitu, gratis untuk digunakan, mudah untuk memulai, memungkinkan untuk membuat game untuk berbagai macam platform, dan memiliki komunitas yang siap membantu.

SMA Negeri 6 Palembang telah memiliki ekstrakurikuler komputer untuk mengasah bakat dan minat siswa-siswi pada bidang informatika dan teknologi seperti mempelajari bahasa pemrograman, membuat website, dan wawasan mengenai dunia komputer. Sedangkan untuk pembuatan game sendiri belum pernah dilakukan oleh siswa siswi karena keterbatasan tenaga ahli di SMA Negeri 6 Palembang. Oleh karena itu, kegiatan pengabdian ini dilakukan dengan tujuan antara lain adalah memberikan wawasan kepada siswa dan siswi SMA Negeri 6 Palembang dalam menggunakan aplikasi GDevelop untuk membuat game atau permainan sehingga dapat menambah keterampilan siswa-siswi tersebut.

\section{METODE}

Metode Pelaksanaan Pengabdian Kepada Masyarakat yang telah dilakukan pada tanggal 07 Februari 2020 di SMA Negeri 6 Palembang adalah berupa kegiatan pelatihan yaitu dengan memberikan materi mengenai pembuatan game dengan menggunakan aplikasi G-Develop untuk Siswa/l di lingkungan SMA Negeri 6 Palembang. Kegiatan pengabdian ini dilakukan dalam tiga tahap, antara lain yaitu tahap perencanaan yang terdiri dari studi lapangan, analisis kebutuhan dan perizinan pengabdian, tahap implementasi dan tahap evaluasi, dapat dilihat pada Gambar 1.

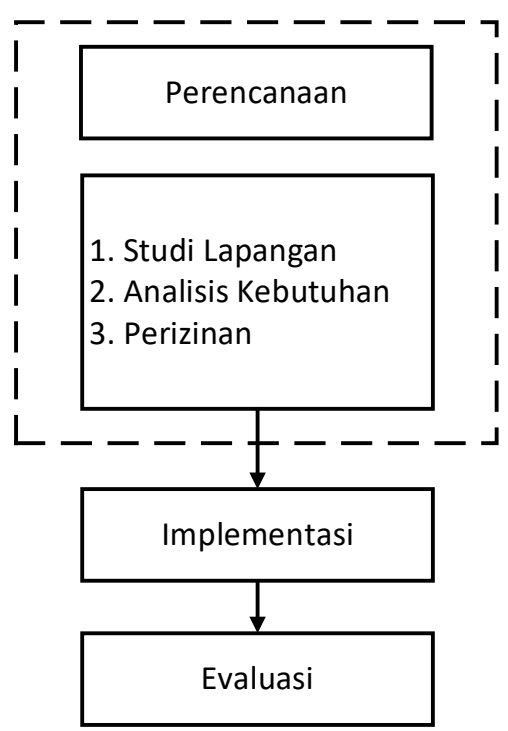

Gambar 1. Tahapan Kegiatan Pengabdian Kepada Masyarakat

Berikut ini adalah tahapan pelatihan pada kegiatan pengabdian yang dilakukan :

1. Perencanaan

Pada perencanaan tim pengabdian melakukan persiapan untuk studi lapangan dan kemudian tim pengabdian melakukan wawancara dengan pihak mitra dalam hal ini adalah SMA Negeri 6 Palembang mengenai kebutuhan dari pihak sekolah. Analisis kebutuhan sangat diperlukan untuk mengetahui informasi, permasalahan dan kondisi yang ada sehingga tim dapat mengetahui perbedaan kondisi yang diharapkan dengan kondisi yang ada saat ini serta tim dapat mempersiapkan materi dan bahan pelatihan yang diperlukan untuk menunjang kegiatan berjalan dengan baik dan efektif. Tahap terakhir dari perencanaan adalah pengurusan perizinan baik dari pihak sekolah maupun pihak kampus.

2. Implementasi

Kegiatan pengabdian dilakukan pada hari Jumat, tanggal 07 Februari 2020, Pukul 13.30 WIB sampai dengan 17.30 WIB yang bertempat di Ruang Kelas SMA Negeri 6 Palembang.

3. Evaluasi

Evaluasi pada pelatihan tersebut dilakukan selama proses berlangsung hingga akhir pelatihan yaitu melakukan diskusi, tanya jawab dengan peserta pelatihan dan memberikan tautan kuesioner kepada 20 peserta menggunakan google form. Evaluasi dilakukan dengan menggunkan metode skala likert. Skala Likert digunakan untuk mengukur sikap, pendapat dan 
persepsi seseorang atau sekelompok orang tentang suatu fenomena sosial (Sugiyono,2010). Tabel 1 menunjukkan skor skala penilaian Likert.

Tabel 1. Skor Skala Likert

\begin{tabular}{clc}
\hline No & Keterangan & Skor \\
\hline 1 & Sangat Tidak Setuju & 1 \\
\hline 2 & Tidak Setuju & 2 \\
\hline 3 & Ragu - ragu & 3 \\
\hline 4 & Setuju & 4 \\
\hline 5 & Sangat Setuju & 5 \\
\hline
\end{tabular}

\section{HASIL DAN PEMBAHASAN Instalasi GDevelop}

Sebelum memulai pembuatan game, para peserta diminta untuk mengunduh aplikasi pembuat game yang bernama GDevelop pada situs https://gdevelop-app.com/ yang dapat dilihat pada Gambar 2. Pada halaman web GDevelop tersebut diberikan dua acara penggunaan aplikasi. Pertama, pengguna bisa mencoba aplikasinya secara online melalui halaman web dengan browser yang digunakan tanpa menginstall aplikasi. Kedua, pengguna bisa mengunduh aplikasi dan melakukan instalasi pada komputer dan dapat bekerja secara offline.

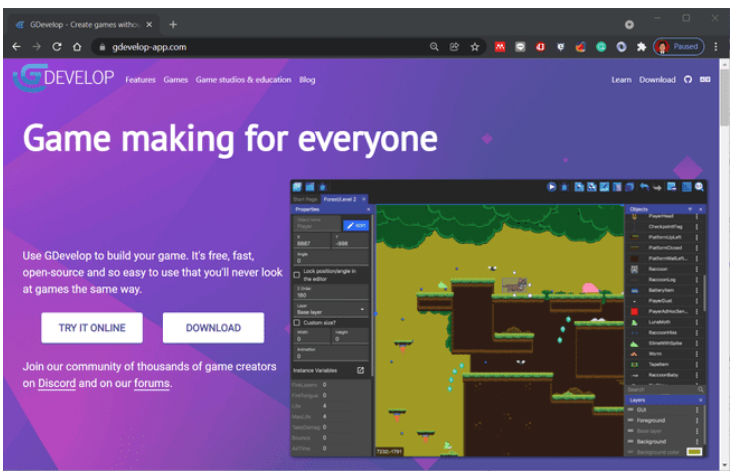

Gambar 2. Halaman download aplikasi GDevelop

Namun yang digunakan untuk pelatihan pada siswa-siswi di SMA Negeri 6 Palembang adalah dengan mengunduh dan menginstall aplikasi di PC/laptop sehingga dapat bekerja secara offline tanpa menggunakan koneksi internet. Setelah proses instalasi selesai maka GDevelop bisa langsung digunakan. Gambar 3 adalah tampilan utama aplikasi GDevelop. Terdapat dua menu pilihan pada tampilan utama aplikasi GDevelop.

1. Open Project: menu ini digunakan apabila sudah memiliki project game GDevelop sebelumnya dan ingin membuka kembali dan melakukan modifikasi terhadap project tersebut.

2. Create $A$ New Project: menu ini digunakan untuk membuat sebuah project game baru dari GDevelop.

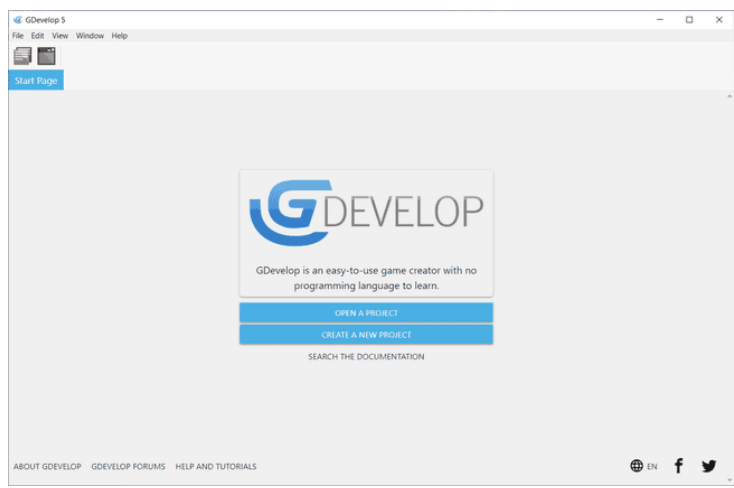

Gambar 3. Tampilan utama aplikasi GDevelop

\section{Membuat Game Platformer}

Apa itu game platformer? Apakah pernah memainkan game Mario Bros dan lain sebagainya pada zaman Console Nintendo, Sega ataupun Playstation? Game tersebut adalah game yang bertipe Platformer dimana pemain harus melompat untuk melewati rintangan dan menyelesaikan game tersebut. Untuk membuat game dengan GDevelop, pertama harus memilih menu Create A New Project. Selanjutnya akan muncul menu pilihan tipe game yang dapat dilihat pada Gambar 4.

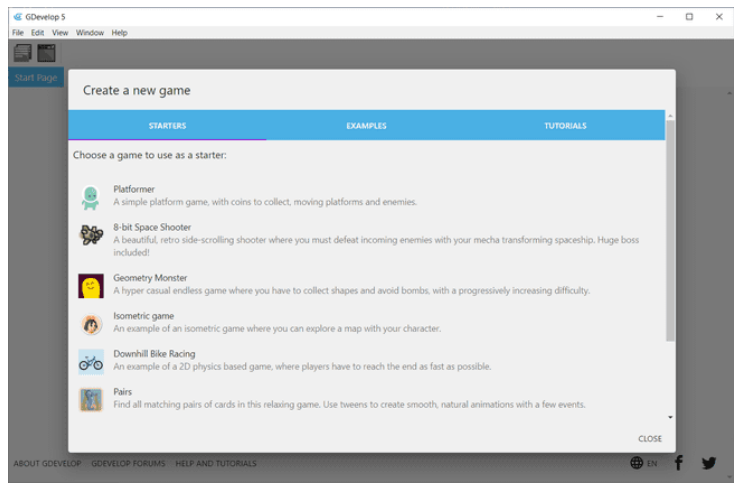

Gambar 4. Menu pilihan game pada GDevelop

Sebelum memilih pilihan selanjutnya, pengguna perlu menentukan tempat penyimpanan untuk project game yang akan dibuat seperti pada Gambar 5. Pengguna perlu melakukan scroll ke bawah untuk menemukan menu pengaturan penempatan file project game yang akan dibuat. Setelah menentukan tempat penyimpanan project game, pengguna dapat memilih menu "Empty Game" untuk membuat game platfromer baru dengan tempat penyimpanan project sesuai keinginan. 


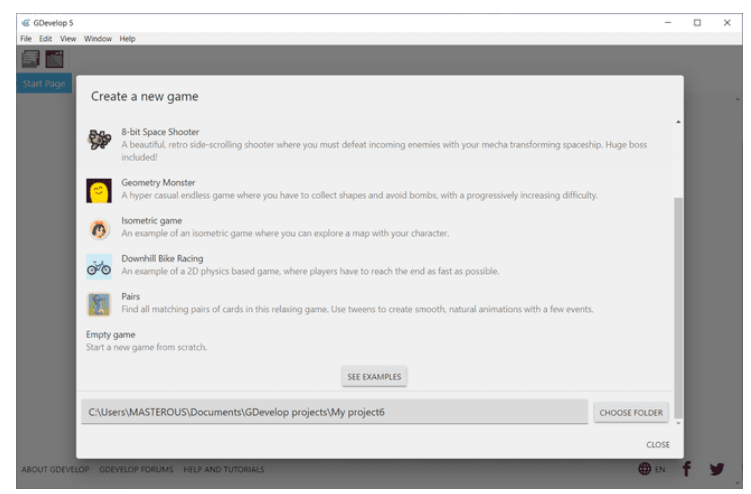

Gambar 5. Pilihan penentuan tempat penyimpanan project game

Selanjutnya akan ditampilkan menu pengaturan project terlebih dahulu. Pada tahap ini, pengguna diminta untuk melakukan beberapa pengaturan game yang akan dibuat. Menu pengaturan project game dapat dilihat pada Gambar 6.

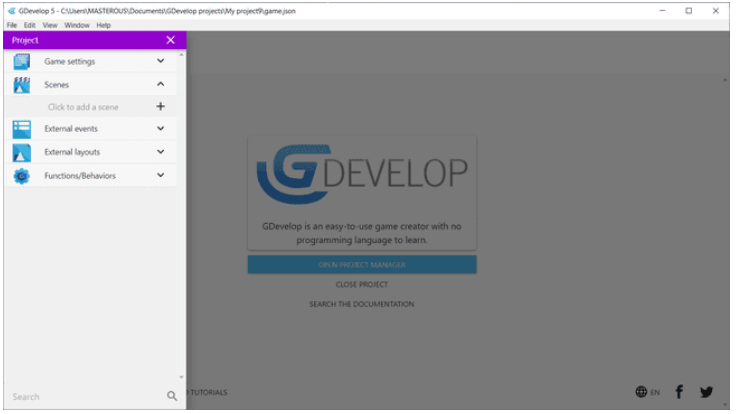

Gambar 6. Menu pengaturan project game

\section{Melakukan Pengaturan Game}

Untuk melakukan pengaturan pada game, pengguna dapat memilih menu Game Settings pada menu Project yang dapat dilihat pada Gambar 7. Menu-menu pada Game Settings adalah sebagai berikut.

1. Properties: menu ini digunakan apabila Anda ingin memiliki mengubah nama game, versi game, nama package (diperlukan untuk game yang akan dijalankan pada perangkat Android dan iOS) , nama pembuat game, resolusi game yang akan dibuat (standar width : 800, height : 600), minimum FPS, maksimum FPS, dan pengaturan AdMob.

2. Global variables: menu ini digunakan untuk membuat variabel secara global agar dapat diakses dan dimanipulasi dari mana saja pada saat pengembangan game.

3. Icons: menu ini digunakan untuk menambahkan icon untuk keperluan game Desktop, Android, dan/atau iOS.

4. Resources: menu ini digunakan untuk menambahkan resources pada game.

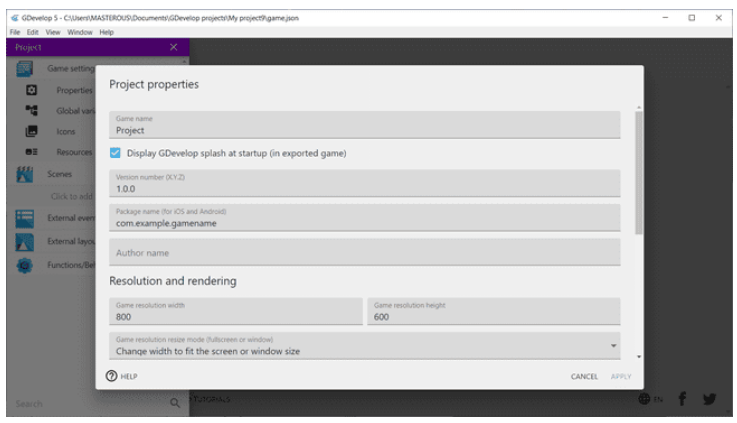

Gambar 7. Menu Game Settings

\section{Membuat Scene}

Untuk membuat scene, dapat menggunakan menu Click to add a scene (Gambar 8). Dengan mengklik tombol plus (+) di sebelah kanan menu "Click to add a scene", maka akan dibuatkan scene baru untuk gamenya.

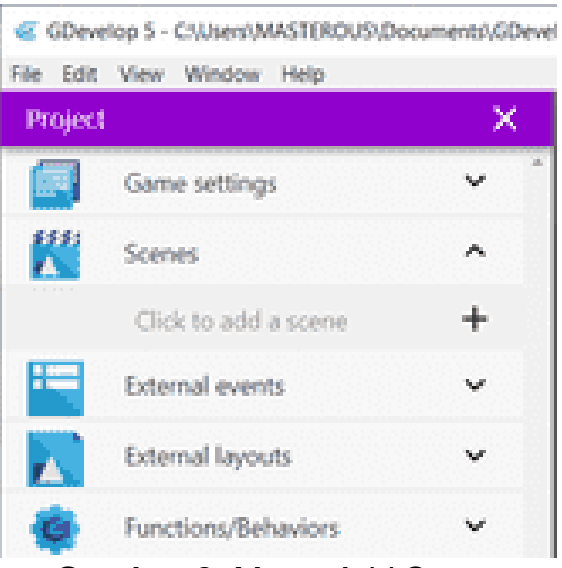

Gambar 8. Menu Add Scene

Selanjutnya akan dibuatkan scene baru dengan nama "NewScene" (Gambar 9). Pengguna dapat mengubah nama scene dengan cara memilih menu "Rename" yang ada di menu samping. Kemudian untuk memulai scene, dapat memilih scene yang baru saja dibuat.

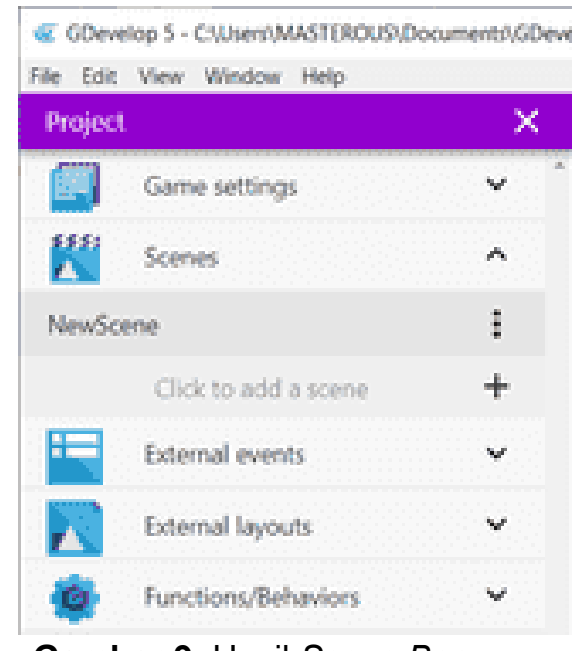

Gambar 9. Hasil Scene Baru 


\section{Menambahkan Object}

Untuk menambahkan object di dalam scene game, pertama-tama klik tombol plus (+) di sebelah kanan menu "Add a new object" (Gambar 10). Menu ini terletak di bagian kanan pada scene. Setelah memilih menu untuk menambahkan object, maka akan ditampilkan menu untuk menentukan tipe object yang akan dibuat. Pilihan tipe object dapat dilihat pada Gambar 11.
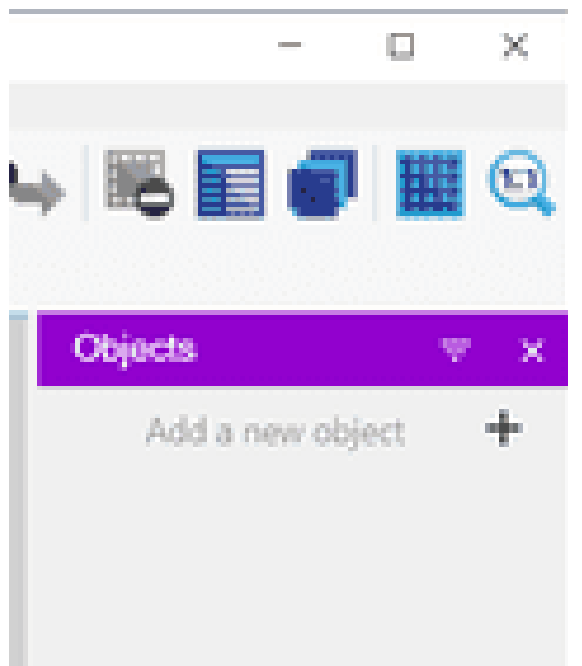

Gambar 10. Menambahkan object baru

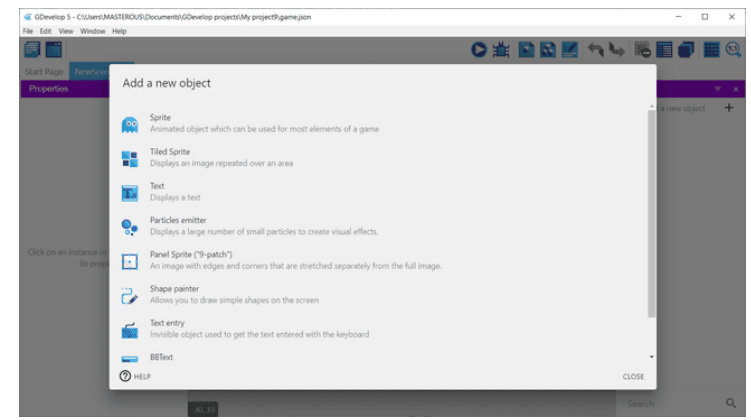

Gambar 11. Pilihan tipe object

Untuk membuat object player, pertama buat object dengan tipe Sprite dan beri nama "Player". Kemudian tambahkan animasi dengan cara menekan menu "Add an Animation +" (Gambar 12). Selanjutnya pilih beberapa gambar karakter untuk animasi diam dan beri nama animasi dengan nama "Diam".

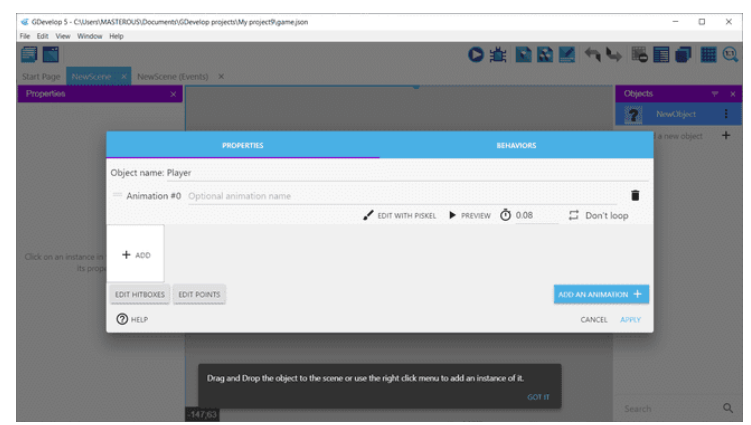

\section{Gambar 12. Menu Add Animation pada Object}

Selanjutnya tambahkan animasi lari untuk object Player dengan cara yang sama, yaitu dengan memilih menu "Add an Animation +" kembali. Selanjutnya pilih beberapa gambar karakter untuk animasi lari dan beri nama animasi dengan nama "Lari". Buat kedua animasi dengan status loop agar animasi tetap berulang secara terus menerus. Penambahan beberapa animasi dapat dilihat pada Gambar 13.

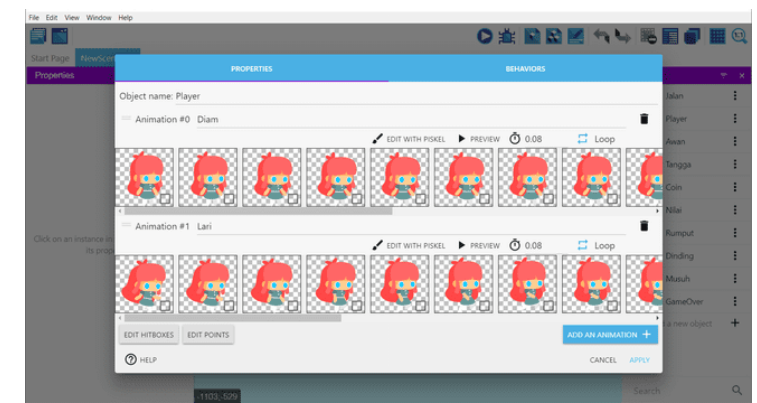

Gambar 13. Penambahan lebih dari satu animasi karakter

Setelah itu, tambahkan behaviors untuk object Player dengan cara memilih menu "Add a Behavior To The Object +". Selanjutnya pilih "Platformer Character" untuk menjadikan object sebagai karakter utama. Menu pada langkah penambahan behaviors dapat dilihat pada Gambar 14, Gambar 15, dan Gambar 16.

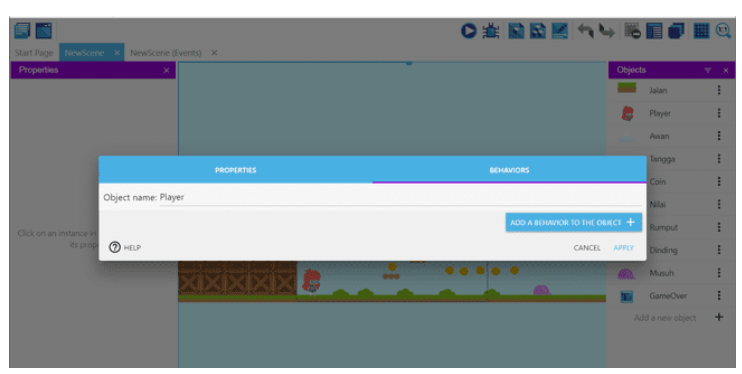

Gambar 14. Penambahan behaviors (1)

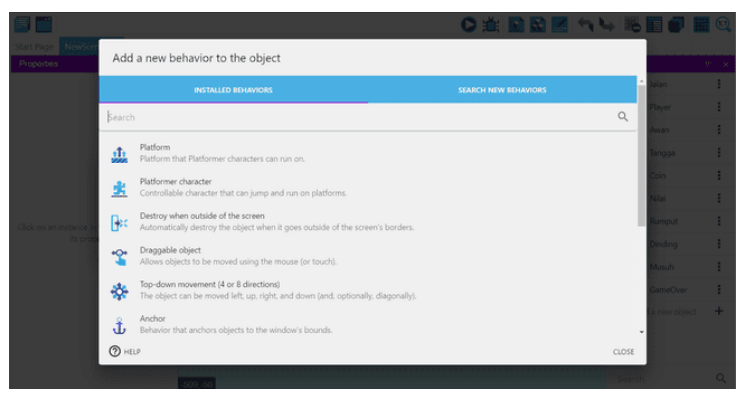

Gambar 15. Penambahan behaviors (2) 


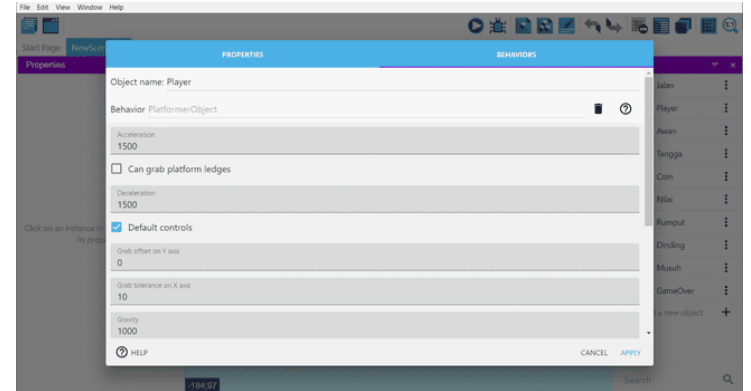

Gambar 16. Penambahan behaviors (3)

Untuk membuat arena jalan pada game platformer, pengguna perlu membuat tipe object "Tiled Sprite" dengan behaviors "Platform" yang dapat dilihat pada Gambar 17.

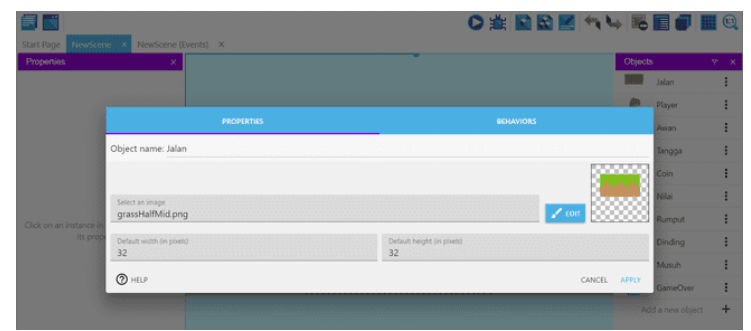

Gambar 17. Penggunaan object Tiled Sprite

\section{Menampilkan Object ke Scene Game}

Untuk menampilkan object yang sudah dibuat ke area scene, pengguna cukup menyeret object ke area scene (drag and drop) sehingga akan tampil di area scene seperti pada Gambar 18.

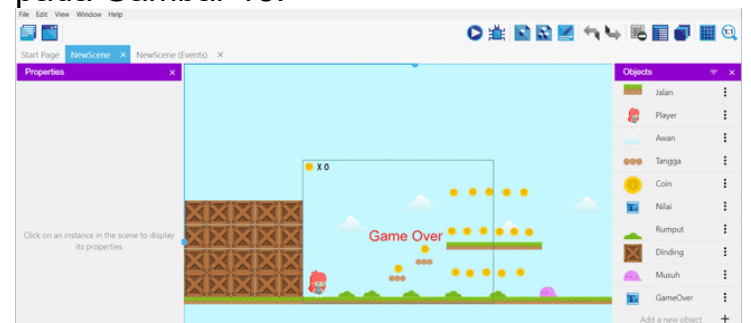

Gambar 18. Menyeret object ke scene game

\section{Menambahkan Event}

Untuk menambahkan event, pengguna cukup mengikuti langkah seperti pada Gambar 19.

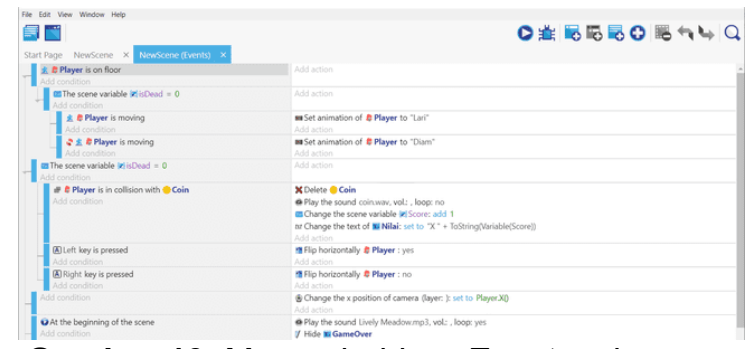

Gambar 19. Menambahkan Event pada game

\section{Menjalankan Game}

Untuk menjalankan game yang sudah dibuat, cukup menekan tombol Run sehingga akan tampil jendela preview game seperti pada Gambar 20.

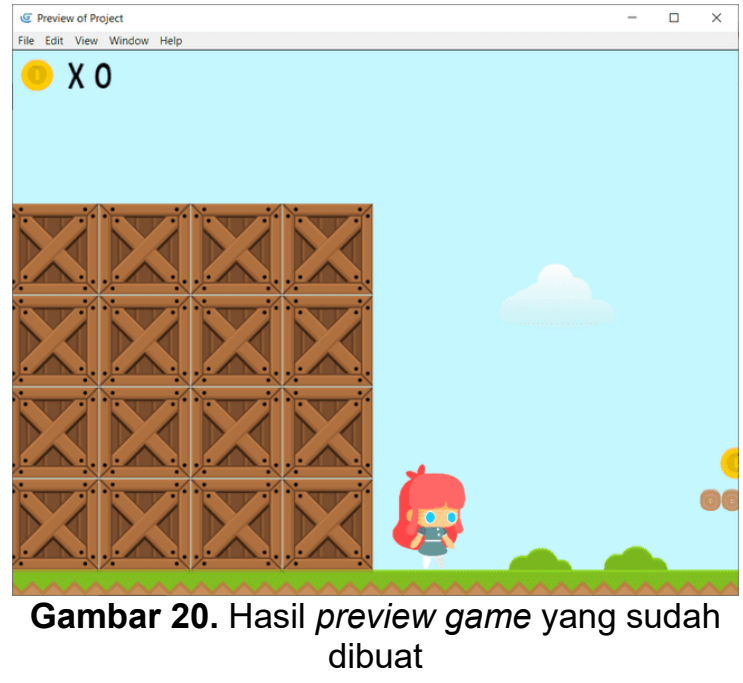

\section{Pelaksanaan Kegiatan}

Kegiatan pelatihan pembuatan game dilaksanakan di laboratorium komputer SMA Negeri 6 Palembang yang dihadiri siswa-siswi yang berjumlah kurang lebih 25 orang. Pelaksanaan kegiatan dimulai dengan memberikan instalasi aplikasi GDevelop sebagai awal persiapan sebelum pelatihan dimulai oleh tim pengabdian. Setelah proses instalasi aplikasi GDevelop selesai dilakukan pada laboratorium komputer maka dilanjutkan dengan penjelasan oleh instruktur pelatihan.

Pada kegiatan ini, game yang dibuat adalah game dengan tipe platformer. Untuk resource kebutuhan dalam mendukung pembuatan game seperti gambar karakter, gambar objek koin, suara bermain, dan lain-lain disediakan oleh tim pengabdi. Akan tetapi semua resource tersebut juga bisa diunduh di portal penyedia game resource lainnya secara gratis. Setiap instruksi tahapan pembuatan game yang diberikan diberi waktu lebih untuk siswa agar mereka bisa berkreasi sendiri untuk membuat arena permainan. Hal ini bertujuan untuk memberikan kesempatan siswa-siswi untuk mengeksplorasi pembuatan game mereka.

Selama kegiatan berlangsung, setiap anggota tim pengabdi membantu para siswa yang mengalami kendala dalam proses pembuatan game yang dapat dilihat pada Gambar 21, Gambar 22, Gambar 23, dan Gambar 24. 


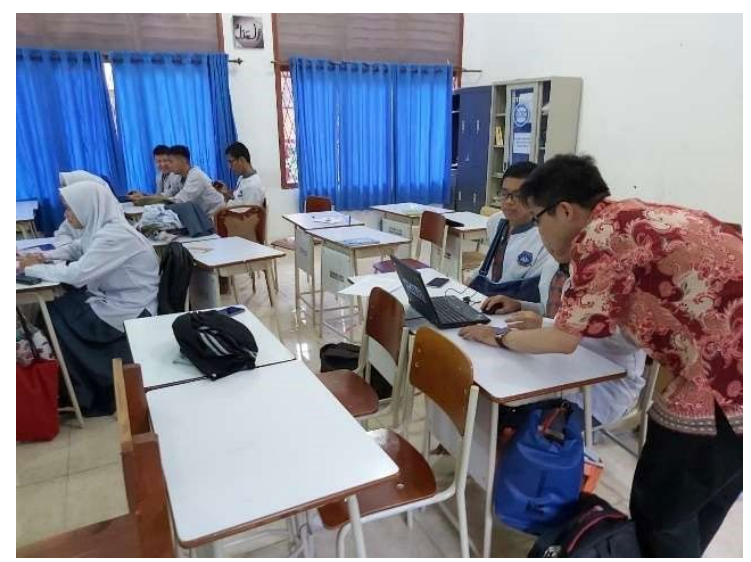

Gambar 21. Anggota Tim sedang berinteraksi dengan peserta (1)

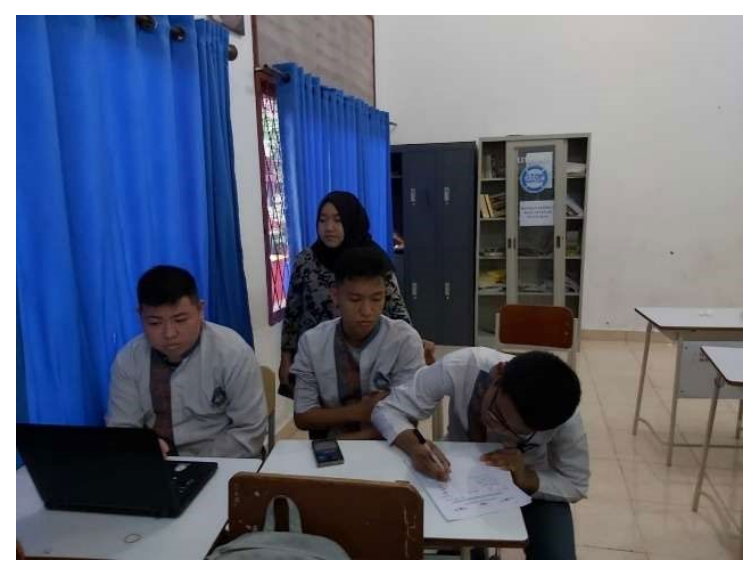

Gambar 22. Anggota Tim sedang berinteraksi dengan peserta (2)

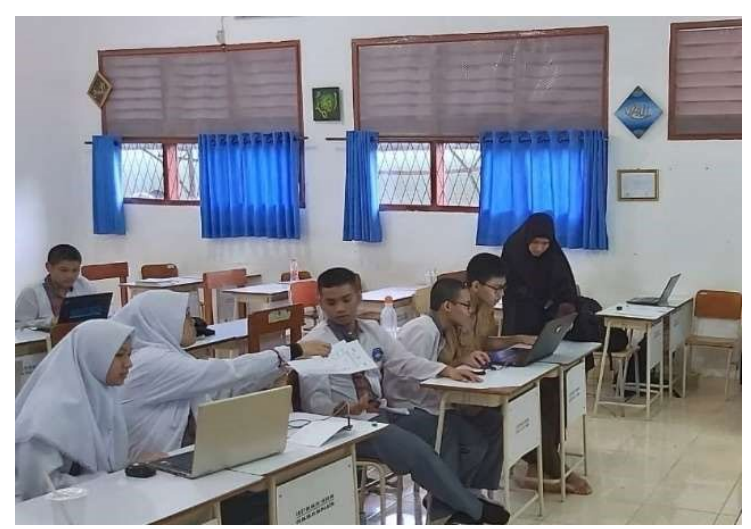

Gambar 23. Anggota Tim sedang berinteraksi dengan peserta (3)

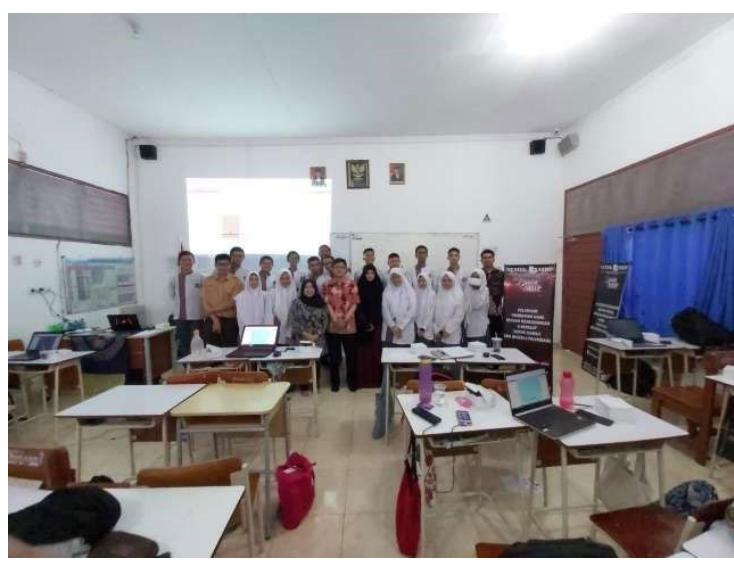

Gambar 24. Foto Bersama Tim dan Peserta Pengabdian

\section{Evaluasi Kegiatan}

Setelah kegiatan pelatihan selesai, tim pengabdian juga melakukan evaluasi pada kegiatan pelatihan dengan memberikan tautan kuesioner kepada 20 peserta menggunakan google form. Butir pertanyaan pada kuesioner yang diberikan pada peserta dapat dilihat pada Tabel 2.

Tabel 2. Pertanyaan dan Hasil Persentase

\begin{tabular}{clc}
\hline No. & Butir Pertanyaan & Persentase \\
\hline 1 & $\begin{array}{l}\text { Penyampaian materi } \\
\text { pelatihan sangat } \\
\text { memuaskan }\end{array}$ & $96 \%$ \\
\hline 2 & $\begin{array}{l}\text { Jawaban yang } \\
\text { diberikan pemateri } \\
\text { sangat memuaskan }\end{array}$ & $98 \%$ \\
\hline 3 & $\begin{array}{l}\text { Kegiatan pelatihan } \\
\text { sangat interaktif }\end{array}$ & $94 \%$ \\
\hline 4 & $\begin{array}{l}\text { Pengetahuan baru } \\
\text { bertambah setelah } \\
\text { dilakukan pelatihan }\end{array}$ & $99 \%$ \\
\hline 5 & $\begin{array}{l}\text { Kegiatan pelatihan } \\
\text { sangat bermanfaat }\end{array}$ & $97 \%$ \\
\hline & & \\
\hline
\end{tabular}

Tabel 3. Hasil Perhitungan dengan Skala Likert

\section{Total Peserta : 20 siswa-siswi}

\begin{tabular}{|c|c|c|c|c|c|c|c|}
\hline \multirow{2}{*}{ No. } & \multicolumn{5}{|c|}{ Skor } & \multirow{2}{*}{$\begin{array}{c}\text { Jumlah } \\
\text { Skor }\end{array}$} & \multirow{2}{*}{$\%$} \\
\hline & 1 & 2 & 3 & 4 & 5 & & \\
\hline 1 & 0 & 0 & 0 & 4 & 16 & 96 & 96 \\
\hline 2 & 0 & 0 & 0 & 2 & 18 & 98 & 98 \\
\hline 3 & 0 & 0 & 1 & 4 & 15 & 94 & 94 \\
\hline 4 & 0 & 0 & 0 & 1 & 19 & 99 & 99 \\
\hline 5 & 0 & 0 & 0 & 3 & 17 & 97 & 97 \\
\hline \multicolumn{7}{|c|}{ Rata-Rata (\%) } & 96,8 \\
\hline
\end{tabular}

Hasil perhitungan dari setiap butir pertanyaan yang telah diberikan berupa kuesioner kepada peserta pelatihan dapat dilihat pada Tabel 3. Dari Tabel 3 juga menunjukkan bahwa yang paling mendominasi adalah peserta merasa mendapatkan 
pengetahuan baru semakin bertambah setelah kegiatan pelatihan dilaksanakan di laboratorium komputer SMA Negeri 6 Palembang. Tidak hanya itu, para peserta juga sangat puas mulai dari penyampaian materi, jawaban dari pemateri, suasana yang interaktif serta manfaat yang dihasilkan dari kegiatan pelatihan ini.

\section{SIMPULAN DAN SARAN}

Dari kegiatan pengabdian kepada masyarakat yang telah dilakukan, terdapat kesimpulan, yaitu dengan adanya pelatihan mampu meningkatkan pengetahuan, wawasan dan keterampilan siswa - siswi SMA Negeri 6 Palembang dalam membuat game dengan menggunakan aplikasi GDevelop. Sebagai saran kedepannya adalah agar dilakukan pelatihan lanjutan dengan menggunakan aplikasi lainnya untuk menghasilkan game yang lebih menarik.

\section{DAFTAR RUJUKAN}

Aula, S., Ahmadian, H., \& Majid, B. A. (2020). Analisis dan Perancangan Game Edukasi Student Adventure 2D Menggunakan Scratch 2.0 pada SMK Negeri 1 AlMubarkeya. Jurnal Pendidikan Teknologi Informasi, 4(1), 21-28.

Noemí, P.-M., \& Máximo, S. H. (2014). Educational Games for Learning. Universal Journal of Educational Research, 2(3), 230-238. https://doi.org/10.13189/ujer.2014.02030 5

Qomariah, S., Yusika Rangan, A., \& Yusnita, A. (2020). Peningkatan Pengetahuan Pembuatan Game Dalam Rangka Pengenalan Industri Kreatif pada Siswa di Madrasah Aliyah An-Nur Samarinda. Bantenese Jurnal Pengabdian Masyarakat, 2(2).

Samuel Zirawaga, V., \& Idowu Olusanya Tinovimbanashe Maduku, A. (2017). Gaming in Education: Using Games as a Support Tool to Teach History. Journal of Education and Practice, 8(15). www.iiste.org

Sugiyono. (2010). Metode Penelitian Pendidikan Pendekatan Kuantitatif, kualitatif, dan R\&D. Alfabeta. 